\title{
Basic Functional Literacy for Engineering Students: Towards a Linguistic Definition
}

\author{
Michael P.Jordan \\ Queen's University at Kingston
}

\begin{abstract}
Established categories of grammatical, sociolinguistic and discourse competence and principles of autonomous and ideological literacy are used as the basis for an analysis of errors in submissions for a post-admissions writing test at university level. To complement Crawford's recent (1995) analysis of the test in this journal, emphasis is placed on identifying the significant "job-related" errors of technical substance, including correctness, completeness, precision, and clarity. Some important errors of discourse competence are also discussed. Basic functional literacy is viewed as an inter-dependent amalgam of autonomous and ideological elements of expression which is judged holistically based on linguistic and pragmatic criteria.
\end{abstract}

\section{Background}

\section{The Pedagogical Need}

IT IS OF COURSE PEDAGOGICALLY ABSURD to expect teachers of any technical writing course to provide meaningful instruction when a significant proportion of the students is functionally illiterate in the language of instruction. Yet that is often the case in many English language Canadian colleges and universities today. Increased numbers of immigrants and visa students, especially from the Pacific Rim, coupled with reduced funding in schools for skilled library teaching, ESL instruction and special education, mean that fewer students are capable of benefiting from a technical writing or first-year writing course.

The lack of reliable admissions criteria for writing ability is the real problem. TOEFL test scores tell us very little about the candidates' abilities 
to comprehend or write in English; and the TOEFL essay scores, though more reliable as an indicator, are not readily available internationally. The grossly-inflated marks for graduating high school English in Canada are at best a poor indicator of a student's ability to write in English. Marks in the high 80 s and even the 90 s are no guarantee of basic functional literacy, although marks below 70 do tend to indicate general illiteracy in English. Moreover, school grades for "English" tend to reflect students' abilities to analyse literary texts, and are thus often unreliable indicators of their abilities to express themselves clearly and correctly.

Because of the unreliability of indicators of basic proficiency in written English, every year Canadian colleges and universities find that they have admitted students who are functionally illiterate in written English. One solution is a first-year course with early testing and streaming, with additional time being given to those with severe language and writing problems. Another solution, discussed here, is a post-admissions test, designed to identify the weaker students early in first year and to require them to improve to a minimum level of adult functional literacy (Nafzinger et al, 1976) before being allowed to start a technical writing course. The question then becomes: "What is that minimum level?" To answer that in other than loose aims or goals, we need to establish writing competence in clear linguistic terms.

\section{Defining Basic Functional Literacy}

The difficulty of defining literacy in reasonably concrete terms has been noted by Mikulecky and Drew (1991), who claim that:

Most attempts to define literacy or establish a criterion for determining what is "basic functional literacy" tend to become muddled since literacy is not easily defined.

Both Stubbs (1986) and Street (1994) explain the difficulties of definition and the many possible meanings of the term. In spite of the difficulties, attempts have been made to define basic functional (adult) literacy in rather loose terms, with emphasis on ability to function in society. Friere (1974) claims that literacy is essentially functional as it enables human beings to pursue their common ontological vocation on a basis of equality with one another. This view is extended by Lankshear (1986), who claims 
that literacy also makes students critically aware of their world and enables them to have greater creative control of it.

Langer (1987) cites the following definition given by the National Association of Educational Progress (NAEP) (1986):

...the use of written information to function in society, to achieve one's goals and to develop one's knowledge and potential.

This rather loose definition is echoed in the Foreword of the 1995 report from Statistics Canada, Literacy, Economy and Society, which defines literacy as:

...the ability to understand and employ printed information in daily activities at home, at work, and in the community [and] to achieve one's goals, to develop one's knowledge, and potential.

These definitions rely on task-oriented levels of literacy and criteria for assessment. This differs from the typical approach in schools of studying existing literature or engaging in "creative" writing isolated from the practical realities of society and the workplace.

As the task of universities and colleges is to prepare their students for technical and professional activities, definitions of literacy in the workplace are of special significance to us here. Askov and Aderman (1991) discuss this issue and note the 1988 amendments to the (USA) Adult Education Act, which provide a general definition for workplace literacy as written and spoken language, math and thinking skills used for job tasks. Chisholm and Campbell (1990) use the term "workforce literacy" to indicate the basic skills needed to function effectively in the economy.

Askov is later (1993) more specific in her definition of workplace literacy, identifying four "clients" for literacy instruction in the workplace (students, unions, management, and the "literacy organisation"). The last category includes state mandates and organisations involved with funding requirements; for our interest here, the wider literacy organisation includes provincial professional associations and the Canadian Engineering Accreditation Board. The special needs for academic groups and professions is recognised in the work of the International Association for the Evaluation of Educational Achievements (Purves, 1987), noting that:

...in many disciplines, as well as in certain professions that demand a great deal of writing, individuals learn to write according to certain 
explicit and implicit conventions that affect patterns of organisation, syntax, phrasing and even selection from the lexicon (Purves and Takala, 1982).

This is certainly true for technical writing, and thus we need to recognise factors other than grammar in a meaningful definition of basic adult literacy for engineers, technologists, and technicians.

\section{Autonomous and Ideological Views}

Early views of literacy (e.g. Goody, 1968) regarded it as an autonomous, almost mechanical, concept isolated from practical job-related tasks. O'Neil (1970), however, suggested two levels of literacy:

Make a distinction: being able to read means that you can follow words across the page, getting generally what's superficially there. Being literate means that you can bring your knowledge and experience to bear on what passes before you. Let us call the latter proper literacy; the former improper.

Street (1984), reinforced by Lankshear and Lawler (1987), rejects the autonomous view of literacy as a skill isolated from practice. They claim there is no such thing as "literary essence" lying behind the social practices of reading and writing, and that we need "to understand literacy in terms of concrete social practices” (Street, 1984, p. 95). Thus Street's “ideological” view of literacy concentrates on the specific social circumstances of reading and writing. This view is echoed by the NAEP (1986):

Language is seen not as a set of independent skills associated with reading and writing but the application of particular skills for special purposes for special contexts.

We can recognise the two types of literacy from a cartoon (Kingston Whig Standard, May 10,1997), in which a man, loitering on a park bench, is asked by an indignant passer-by whether or not he can read the "No Loitering" sign on the bench. His response of "Yes" leads to the question "Well then?" and the loiterer then asks what "loitering" means. He can read the sign but does not know what it means-and so sits on the bench. The loiterer is literate in that he can "read" in O'Neil's sense, but he is 
illiterate in the sense that he cannot understand the message. This "ideological" literacy involves much more: the semantic meaning of words in a language, special meanings in given contexts, comprehension of a message from the words and grammatical structures presented, and choice of appropriate terms during encoding.

The fully ideological view relies solely on comprehension of the message as the criterion for literacy. This is too extreme, however, as many messages can be understood but would still reflect illiteracy because of their failure to follow accepted norms of the language. Apart from restricted exceptions for very special purposes (such as knitting patterns, parade ground commands or Caterpillar English), all uses of a given language require a central core of phonetic, morphological, and syntactic language knowledge and ability. Without this central core, a student is not literate for any job-related purpose. This is recognised by Canale's levels of literacy (Duran et al, 1985):

Grammatical Competence Mastery of the language code (sentence structure, vocabulary, word formation, spelling).

Sociolinguistic Competence Appropriateness of use of meaning (topics, attitudes, functions) and forms (register, form, expression).

Discourse Competence Combining meanings and forms (pronouns, transitions, coherence) and organised meaning (development, consistency, balance).

Strategic Competence Mastery of strategies to compensate for breakdowns in communication and enhance rhetorical effects.

Stubbs (1986) provides some linguistic background for the concept of the sociolinguistic element of literacy. While this and the other categories are imprecise, incomplete, and overlapping, they do point to the need to define basic functional literacy in terms of different levels of linguistic capability - not just "grammar." Their vagueness in linguistic terms should encourage us to seek clearer definitions of literacy both for the central core of language literacy and also for more specific, profession-related tasks for technical and engineering students. 


\section{A Job-Related Test Of Literacy}

\section{Test Details}

The material used as the basis for the following analysis comes from responses to the Faculty of Applied Science's Post-admissions Writing Test at Queen's University, Kingston, Ontario, Canada. Together with a pretest trial in the spring of 1995, the test has been given five times, and meaningful results are now becoming available. The aim of the test is to allow students with at least a minimum literacy level to proceed directly to a course in technical writing without having to take an ESL course in functional English. The test evaluates each student's "pragmatic literacy" (Wormald, 1977) — the ability to produce practical goal-oriented writingrather than the "cultured literacy" (Hirsch, 1987) largely of personal selfexpression. The TOEFL writing test and general essay questions are examples of this second type.

The test described here evaluates each student's ability (a) to read and understand written instructions, (b) to understand and make notes of information presented orally, and (c) to write a job-related document from the information given to them. This information is presented to the students in a haphazard order and in a colloquial and verbose manner; it also contains some irrelevant material, which students are expected to omit from their written submissions. The information, note taking, and writing all occur under test conditions. The broad aims of the test follow the approach articulated by Gray (1956) and the UNESCO (1957) report on world literacy, which view literacy as a continuum of reading and writing skills, but applied in a social context. However, the Queen's test also evaluates the literacy skills of listening, understanding, and note-taking—all essential elements for participating effectively in advanced education.

A pilot test, given to 103 second-year electrical and computing engineering students, has already been analysed by Crawford (1995), who explains and classifies many of the types of literacy problems encountered. This discipline of engineering attracts many ESL students and also native users of English who have concentrated on mathematical principles at the expense of language skills. There is, thus, a significantly higher proportion of students in this department, compared with others in the faculty, who have difficulty with written English. 
The real test has been administered to all first-year engineering students at Queen's. Although this test population is considerably different from those in the pilot test, those who fail the real test share the same linguistic inadequacies as those who failed the pilot test - but for a lower proportion of those tested. Therefore, the discussion of language difficulties presented here is comparable with the lower of the "two Gaussian (or normal) distributions" of marks identified by Crawford representing the abilities of students with ESL problems or serious weaknesses with English as their native language.

The contents of the first three real tests were presented impromptu directly from the previously finished document, which was then used as the "answer guide" for evaluation. The contents of the latest two tests were first given in this way on a tape recorder, then transcribed, and, finally, read to the students. It was thought that this second method would give greater control over the material presented and would also allow different readers with different accents to present the material. However, there is no evidence that this change in presentation of the information had any noticeable effect. The material presented orally to students in the April 1997 test appears here as Appendix A, and the "answer guide" (what, ideally, students were expected to produce) is Appendix B.

Most of the tests have been based on safety or accident reports, which have special organisational requirements. Above all, though, completeness and clarity are important, as the report the students present must be technically precise in the locations and descriptions of the hazards noted and/or the causes of the accident. Thus, this test is designed to be jobrelated to the needs of engineering, both in what it evaluates (reading, comprehension of oral material, note-taking, and writing), and also in the technical content and its organisation, albeit for a short and relatively simple topic. As it is assumed that the students taking the test have not written such communications before, they are given written instructions regarding their role, the objectives for the report, and expected format. Part of the test, of course, is that they are able to understand and follow these instructions.

\section{Motivations for the Test}

The need for such a test came from several sources. The first was that $30-40 \%$ of students in electrical engineering were dropping out of, or failing, a required third-year course in technical writing because of their low literacy 
levels in English. This was taking far too much time in personal instruction (which is better done in ESL classes), and was adversely affecting the instructors' ability to present a meaningful course to students who were at least reasonably literate in English.

In addition, it was realised that some students, many of whom were very significantly below an acceptable level of literacy in English, had already passed an earlier course in first year in which they had been required to submit a written report as a member of a group. Clearly, students who were functionally illiterate in English were somehow meeting the writing requirements of the first-year course. It therefore seemed likely that students were graduating from Queen's with that same unacceptable level of literacy. This was possible because some departments do not require a technical writing course (some require only group submissions in a "thesis" course), and there was no formal departmental or faculty-wide test of literacy before graduation. Such a situation could —and should-raise serious questions for accreditation of the programs.

These problems were highlighted by the Kantor case, published by the Professional Engineers of Ontario (PEO) in 1987, and included here as Appendix C. In this case the PEO disciplinary Committee found Mr. Kantor "guilty of professional misconduct" because "the Committee concluded that Mr. Kantor's report was so badly written that it could not be sure of exactly what Mr. Kantor was saying or what was meant by some of his statements." The summary notes that:

This finding was based on the fact that the feasibility report or study prepared by Mr. Kantor did not meet the criteria generally considered necessary to provide a meaningful electrical engineering report as it contained statements that were poorly written, contradictory and confusing, and that it contained errors and indicated a lack of knowledge of the basic theory of electrical engineering.

The finding was based legally on the definition of "Negligence" found in Section 86(2)a of Regulation 538/84 made under the Professional Engineers Act of Ontario. This states that:

In this Section, negligence means an act or omission in carrying out the work of a practitioner that constitutes a failure to maintain the standards that a reasonable and prudent practitioner would maintain in the circumstances. 
For technical writing, this is a vague-though clearly enforceabledefinition of adult functional literacy.

The Kantor case provides a compelling motivation for ensuring the basic functional literacy of all graduating engineering students. It might also be argued that any engineer, department, or faculty who graduates a student who is below a basic level of literacy in written English might also be found guilty of professional misconduct. As negligence includes omission as well as a positive act, engineering faculties cannot pretend the problem does not exist or turn a blind eye. Only organised tests under controlled examination conditions will provide the basis for a valid test of written literacy and will, therefore, show that engineering educators have taken due care in meeting their responsibilities.

Professional and accreditation bodies must also accept their responsibilities. While provincial associations insist on examinations for ethics, they have no such requirements for literacy in English and rely on educational institutions. Also, the Canadian Engineering Accreditation Board, although its committees have been asking for years for more work in communications for accredited programmes, has yet to insist on at least demonstrable minimum literacy levels in written and oral presentation of technical information.

\section{Evaluation of Test Results}

The evaluation of the written test results is achieved in two stages. First of all, students' work, in groups of about 100, is judged independently by two engineering faculty, who mark each submission as "Pass," "Marginal," or "Fail." Their assessments are based purely on their judgement of what a "reasonable and prudent practitioner would maintain in the circumstances;" that is, it is a subjective evaluation, judged by engineering peers in the same way that such documents might be assessed in job-related conditions in real engineering circumstances. However, as judges recognise that some students will take one or more writing courses before graduating, they are primarily concerned with ensuring a minimum capability with the language. Submissions that are failed by one or both examiners, or who have two "marginal" assessments, proceed to the next stage of assessment; all others are passed without further assessment.

The second stage of evaluation is by an engineering linguist, who grades each paper from 0 to 10 (usually, though, 1 to 5 ) with 4 being a marginal pass and 3 the highest level of failure. At present, the judgement 
is still largely subjective, although of course a much greater knowledge of language use and structure is brought to bear in the assessment. Because of this, usually about $25 \%$ of the submissions that fail the first stage are passed at this second stage, though often marginally. The final assessments are becoming more objective with the recognition of types of errors and their importance as identified in this paper.

Part of the judgement of pass or fail at the second stage is the criterion of whether the student is likely to pass a second or third-year technical writing course without the need for extraordinary amounts of personal tuition. This means that many mistakes of the same linguistic type are likely to be forgiven, as instruction on, and practice with, this sort of error should yield significant results. In contrast, the occurrence of many different types of errors indicates a general inability with the language which the student might not be possible to correct in a 12-week course. The assessment is a balance between the traditional "autonomous" and "ideological" views of literacy, in which both basic language skills and use of the language for the purpose intended are being assessed. In Canale's terms, elements of grammatical, sociolinguistic, and discourse competence are all required to pass, though emphasis is on the first of these.

\section{General Principles}

\section{Initial Classification of Errors}

The pilot test mentioned earlier was analysed in some detail by Crawford (1995), who noted a "double Gaussian curve" created by the performances of two sets of students. The lower curve was correlated with ESL and other students who experienced great difficulty in passing the more advanced writing course after two or more attempts. The test proved to be a reasonable forecast of the difficulties some of the students (and the instructor) would have in the writing course itself.

Crawford also provides an initial analysis of the types of errors that occurred in the submissions. These included both "autonomous" and "ideological" errors in all of Canale's first three groups, but mostly in the first two. As Canale's categories are so imprecise, a more accurate connection between those categories and Crawford's practical results is not possible. 
Crawford's largest category was "faulty word choice," which she subdivides into groups labelled "strange wording," "awkward wording," and "confused wording." Non-standard English structure was next in frequency of occurrence, followed by comprehension, plurality, tense, conciseness, spelling, prepositions, agreement, punctuation, clarity, tone, missed items, articles, and precision. Many of these types of errors are essentially quite objective errors of language use-any native English user would recognise them as errors. However, others (such as tone and conciseness) are much more subjective, while still others (such as precision, clarity, and completeness) may require knowledge of the work presented.

\section{The Definition in Principle}

In seeking to define basic functional literacy, we need to be more precise in our meaning of the large category of "faulty word choice." In doing this we also need to understand what sorts of "ideological" errors are being created in functional terms such as comprehension, precision, clarity, and completeness, which are job-related features that reasonable practitioners would expect to get right. We also need to balance such criteria with the need for students to demonstrate significant mastery of the language as an autonomous ability to communicate in most written forms in English.

In principle, we might regard these two opposing views of literacy (autonomous versus ideological) as being integrally complementary, in the sense that both need to be present to achieve basic functional literacy. The traditional idea of allotting, say, $50 \%$ of a total mark to each of these categories is complementary, but fails to ensure that both must be present for a score of $40 \%$ or so. This is the way that students who are illiterate in English are able to achieve quite high scores in high school English and are able to pass first-year engineering courses which require writing ability: the students may receive 5 to 10 out of 50 for their writing ability, and yet pass the course because of high marks on the remainder of the course.

Thus, the only way to assess literacy is to do it independently of other assessments. We might also apply integral complementality of autonomous and ideological elements of literacy by using the geometric rather than the traditional arithmetic mean. In this way, a mark of 10 out of 100 for language ability and 90 out of 100 for job-related features yield only $30 \%$, not the $50 \%$ that an arithmetic mean would yield. As a hypothetical extreme, this 
means that a communication that is excellent from a technical viewpoint, but written without due regard to the structure and grammar of the language, would be unacceptable. It is, of course, hard to imagine such a document, as readers would not be able to understand and judge the effectiveness of the technical statements. Conversely, a beautifully written document in terms of structure, continuity, grammar, etc., which is technically imprecise, incomplete, or wrong would also be unacceptable. Clearly both aspects of the document must be reasonably acceptable for the writer to be regarded as acceptably literate. I believe this reflects how technical documents are judged by peers, as we saw with the Kantor report.

\section{Types of Error in the Kantor Report}

In practice, of course, it is most likely that both types of error will be present in a poor document. A lack of literacy often appears not just as obvious errors in language use, but also as comprehension and expression difficulties in what is said as well as how well it is said. We can see the combination of errors in extracts from the Kantor report, cited in the summary:

(1) As a result of such situation, the insulation of the motor's wires are overheated and overdrayed. Therefore it become a brittle and life of the electrical motors would be drastically reduced (PEO, 1987, No. 2).

On a purely grammatical level, "such" should be "this," "overdrayed" is not an English word, "are" does not agree with the singular head noun "insulation," "become" does not agree with the singular subject "it," the article "a" should be deleted and "the" included before "life;" and perhaps "are" should be "become" and "would be" should be "are." On a discourse level, "of such situation" is unnecessary, the logical signals are overmarked, and the text is verbose. We could rewrite the text as:

(2) This would cause the insulation of the motor's wires to become overheated, dried out and thus brittle, reducing the motor's life.

Now we come to possible ideological errors: the ones we cannot usually correct without full knowledge of the text and the technicalities involved. Are the "motor's wires" in the stator or rotor, or both? And what does "drastically" mean here? Perhaps the text could not be more precise, but perhaps it could. In a literacy test such as that used at Queen's, such questionscan be answered because the information has been provided, and 
therefore students are expected to be adequately complete and precise in their technical statements.

Poor literacy for professional engineers is not simply a matter of the language use appearing illiterate and thus unprofessional. Often the technical content is unclear or is misunderstood, as we see in:

(3) As a result of the above study we can come to conclusion that there is no economical and not practical to keep the installed capacitors who do not improve the Power-Factor to cat the utility bill, but are creating an excessive voltage rise and in long run, would reduce the life of the electrical equipment (PEO, 1987, No. 3).

The writer confuses anticipatory "it" and existential "there," has difficulties with articles, agreement and negations, and confuses "who" and "which." Technically, the summary adds the note:

Testimony indicated that the system was operating satisfactorily without changing capacitors as recommended.

This may have been a misunderstanding, however. Kantor did not say that the system was not running correctly. I believe he was trying to say that the capacitors were not doing their expected job of reducing the power factor and thus lowering the utility bill - and also that they had the adverse effect of increasing the voltage and thus reducing the life of the motors. He therefore suggested their removal. Clearly his literacy level was such that he could not articulate this clearly. Thus, one test of ideological literacy is whether the correct message is understood-certainly not misunderstood-by intended readers.

\section{Some Types Of Ideological Errors}

\section{Applying Grammatical, Sociolinguistic, and Discourse Errors}

The grammatical errors of agreement, articles, tense, and structure signals we see in the previous excerpts and in many poorly written documents are well known, and many texts provide explanations and exercises to help students improve these skills. These errors are best remedied through instruction and practice in ESL programs. Then there 
are the discourse and strategic errors (Duran et al, 1985). Some of these may be dealt with in ESL classes, but many could be covered in a technical writing course for all students rather than as ESL instruction. Thus, these sorts of errors-unless extremely serious — should not by themselves prevent a student from proceeding to a technical writing course.

Much less well understood, however, are the sociolinguistic or ideological errors involved with the substance of the message being conveyed. These are crucial technical errors which are at least as important as the more mechanical errors of language use itself. They include technical precision and completeness, vagueness, and conciseness; these are discussed in detail here. The difficulty with ideological errors is that their cause can be a lack of comprehension of the information, a lack of technical understanding, or a lack of an ability to articulate the ideas well-or a combination of these. This issue is discussed as we proceed.

The examples cited in the remainder of this paper are taken from student submissions for the test described earlier and included here as Appendices A and B. Where there are differences between the meanings of these appendices, the former should be referred to, as this was the material actually presented to the students. Some words in the extracts cited here of special relevance to the discussion are in quotations to facilitate recognition. Obviously all sorts of errors are included in the extracts cited, but only those of specific interest are discussed; because of the large number of errors, [sic] is not used to identify them in the usual way. Although the test was administered to all (ESL and other) first-year students, it is likely that many of the examples cited here are from ESL students. The need for confidentiality and blind assessment by student number prevents further analysis.

\section{Faulty Word Choice}

Out of the 465 errors examined by Crawford (1995), no fewer than 111 were classified as "Unconventional or inappropriate word choice." Rather than following Crawford's sub-divisions of "strange wording" (50), "awkward wording" (27), "words confused" (21), etc., here we will seek to determine the type of error in more functional senses such as lack of comprehension, precision, collocation, etc. We see some of the differences in: 
(4) On the seventh floor, the copy machine in the family launch uses an extensive cord.

The use of "seventh" for "second" is more than just mishearing the information; as all the information is about the basement, first floor and second floor, it should strike the student as odd indeed to have this one item on the seventh floor. That is, some thought should have rectified this error. Use of "copy" rather than "copying" as an attributive adjective should have been corrected; more importantly, as the correct word "coffee" was mentioned no fewer than four times later, students should have corrected any initial mishearing error, even though "copy" and "coffee" are phonetically similar and perhaps even collocationally appropriate. The use of "family" rather than "faculty" is perhaps more understandable, as it is only mentioned once; it is, however, a serious error of collocation, as we can assume that students would not expect to have family rooms in an educational building at a university. Even worse collocationally is "launch" instead of "lounge," which is clearly an unsuitable word for this context. Finally given the later context and some understanding of the technical problem (see Appendix B), the degree adjective "extensive" is clearly unsuitable in place of the type adjective "extension."

There is nothing grammatically or structurally wrong with the student's sentence, of course, and it could be regarded as indicating autonomous literacy. But it is technical nonsense, showing unacceptably low levels of phonetic distinction, comprehension, use of wider discourse clues, collocational understanding, and vocabulary-all elements of ideological literacy. The question of technical level is important here. Although we cannot expect students taking the test to have any specialist technical knowledge, they should have an adequate knowledge of general vocabulary in English_enough to avoid the errors in Example 4. All four errors occurring together in a simple sentence is a clear indication of a low level of ideological-though not necessarily autonomous-literacy.

The advantage of taking a geometric mean of autonomous and ideological capability can be seen from Example 4. With assumed scores of $9 / 10$ for autonomous literacy and (generously) $1 / 10$ for ideological literacy, the arithmetic mean would be $5 / 10$-an easy pass. However, the geometric mean would yield $3 / 10$ (a fail), which is a better indication of the value of the sentence as a message, and also the functional literacy of its writer. 


\section{Homonyms, Malapropisms and Spelling}

Perhaps largely because of over-dependence on computer spell checkers, homonym errors are more common nowadays and are found, in moderation, at acceptable levels of literacy. (That is not to condone them of course!) Malapropisms, however, usually are indications of poor literacy. We see the difference in:

(5) ...to prevent people from placing there mouth directly in contact with the fountain. Apparantly the metal lip is broking off. This broking lip could cut someones mouth and cause the transition of deseases.

While the homonym "there" for the possessive form "their" is a common error not necessarily symptomatic of poor literacy, the malapropism "transition" for "transmission" is an indication of poor literacy. The use of "broking" should be regarded as a grammatical error, as it uses an incorrect "-ing" form instead of the required "-ed" form (broken). Computer software capabilities are relevant here. While spell checkers will note "Apparantly," "broking," and "deseases," we must rely on grammar or style checkers to identify the homonym "there" and the lack of the possessive in "someones." Yet neither will note the malapropism "transition." Thus, this last error should be perceived ideologically as a more serious mistakeone that the student would still make even after the work has been checked by computer software.

Like homonyms, the occasional spelling error is not unusual or an indication of illiteracy. Again spelling errors now appear more frequently as students rely on their spell and grammar checkers to spell for them, and these do have their limitations. When poor spelling becomes symptomatic of illiteracy is a matter partly of frequency, but also of the type of spelling error. Perhaps we must almost expect otherwise literate students to misspell words such as "apparently," "recommend," and "occurrence." However, when we find "plugged," "kettle," and "circuit" all misspelled within two short sentences, we should regard it as an indication of poor literacy:

(6) In addition, the new machine on the second floor is pluged with a cadle and a microwave oven. The circut is not acceptable.

Again the type of error is important. We cannot expect a spell checker to give us the correct spelling based on "cadle," and we would expect students (especially electrical students) to be able to spell "circuit." 


\section{Incompleteness and Vagueness}

In technical writing, we expect writers to provide sufficient information to allow readers to fully understand and act upon the information provided. The writing is deficient if the writer fails to do this, and it can indicate a low level of comprehension and/or descriptive ability if it is significant. The following extract is from a marginal pass submission:

(7) An annual safety inspection was conducted for the Bondar Building. Some problems were identified and must be fixed.... On the basement floor, a large pool of oil was found with sawdust.

The agentless passives fail to say who carried out the inspection and who must remedy the deficiencies. The "basement floor" is far too vague, and should be "the north-west corner of the wind tunnel laboratory." Also the terse "found with sawdust" provides a poor indication of the actual situation (see Appendix A). All this information was given and is relevant for the report.

Location is the greatest problem with incompleteness and vagueness, with many students failing to identify the location of the hazard clearly enough, as we see above. Here is an extract with unclear location as well as an inexact statement:

(8) A room in the basement stores chemicals.

We do not know which room is being referred to; it should be the welding shop. The statement is also inaccurate as there is no room that specifically "stores chemicals." All that is needed is "The welding shop" as the recipient of the report knows that it is in the basement. The problem here may be one of understanding the word "welding," and Example 8 may have been an attempt to avoid the term. Such possibilities need to be taken into account when assessing literacy.

\section{Correctness and Precision}

Some statements are technically wrong:

(9) There is a large storage tank in the north-west corner of the wind tunnel laboratory in the basement. The grease on the floor needs to be cleaned up and should be checked regularly. Also in the basement, the 
north emergency exit sign is obscured by three large garbage cans.

Although the first sentence is very clear, it is completely wrongthere is no storage tank there! Even if there were, that would have no relevance by itself for a safety report unless there was something wrong with it or it was causing an obstruction. The second sentence is inaccurate, as there was a pool of "oil" in that location and not "grease;" this is mentioned twice in the information provided. Readers of Example 9 would also have difficulty understanding what should be checked regularly. Finally, it is the exit door and not the exit sign that is partly obscured. Again, all this information was given to the students, so the distortion is signficant.

As we saw in the Kantor summary, writers of technical information do not have license to write whatever they like. They must present only clear and accurate information to their readers. Extract 9 is acceptable grammatically, but it contributes significantly to a poor technical document and indicates poor comprehension or expression. Thus, it indicates at least a weak level of ideological literacy.

Seyeral errors of correctness, precision, and completeness occur in:

(10) On the north wall of room 209, the exit sign has an arrow pointing to a place that has an accumulation of snow.

First of all, there is no arrow and it was Room 206-matters of correctness. Then, the writer fails to note that the sign is not lit and that the exit leads to a fire escape. And finally, the extract states that the "place" (the fire escape) is covered with snow, whereas it was actually covered with ice-a very big difference from a safety point of view. These are all signs of poor ideological literacy, although we may have to take into account the possibility that some first-year international students may have never seen ice or snow, and may think they are the same.

\section{Missing the Point}

A lack of understanding and/or an inability to express ideas clearly can cause writers to miss the point of some information provided. We see this in:

(11) Firstly the metal lift of the drinking device on the second floor is broken. This could cause a spread of disease if somebody cut his/her mouth when using that device. 
The incorrect word "lift" for "lip" and the vague noun "device" instead of the more specific "fountain" should make us question the literacy of the writer. Added to this, the student has missed the point that the lip prevents drinkers from placing their mouths on the water outlet. The broken lip no longer prevents this, and thus allows the possibility of transmission of disease through saliva. The broken lip presents another hazard in that it could cut someone's mouth. The writer has missed the point.

The point is also missed in:

(12) Also, losed cadimum coils are located away from the box. People may pick up the toxic cadimum and create hazard. I suggest you to post an instruction paper on how to use cadimum solder.

This misses the point that instructions and warnings are on the box containing the cadmium solder. These are quite suitable, but of course are of little use if welders use the material without reading them-which is likely if the solder is not kept with the box at all times. The student's spelling of "cadmium" is problematic given that it was spelled out during the test.

\section{Some Types Of Discourse Errors}

\section{Discourse Errors in Perspective}

Rather than discuss "grammatical" or "autonomous" errors, we have so far concentrated on the "sociolinguistic" errors described by Canale (Duran et al, 1985) or the "ideological" job-related issues of literacy as described by Street (1984) and Lankshear and Lawler (1987). We now need to examine the major errors involved with Canale's "discourse competence," which involves how statements are arranged and connected in meaningful ways to create order, paragraphing, and continuity.

The principles involved with discourse competence are included in technical writing courses, and so errors of this type-unless very seriousshould not be grounds for an assessment below basic functional literacy. However, serious problems with discourse errors could well contribute to such a judgement together with grammatical and/or ideological errors. Often discourse difficulties are further problems the student has to contend with in meeting a minimum level of functional literacy. 


\section{A Sensible Order}

If a document is written in a haphazard order (and remember the information is provided this way), it will be very difficult to provide any meaningful connection or meaning to the paragraphs. The problem is highlighted by:

(13) A drinking fountain with a broken protective lip was on the second floor. It would transmit disease if people drink too far down. A large amount of oil was on the North west corner of the basement. A safe environment should be oil and grease free. The two light bulbs of the exit sign on the south wall of room 105 was not working.

The coffee machine in the lounge area connected the electric socket with an extension cord.

The material could be organised floor-by-floor (basement, first floor, second floor) or perhaps by type of hazard (major hazards, other hazards, and fire exits and equipment), but some sort of organisational pattern is needed for the whole document and for paragraph unity. The above extract provides no such grouping of information and should be seen as an element that could contribute to a judgement of poor literacy.

\section{Poor Connection of Statements}

In addition to grouping information about one topic, students are also expected to connect the facts into reasonably long sentences. This is not achieved in:

(14) On the first floor, the exit sign on the south wall at room 105 is not working. In room 109, a large switch needs to replace. The heat control sensor is badly corrode. Water dripping cause hazards. It needs to be fixed. Half way along the corridor, fire equipments are kept behind the glass door. The glass door is badly cracked and it can cause serious cuts and it needs to replace.

Although all this information relates to hazards on the first floor, essential connections between sentences two to four are missing, and the connections in the last two sentences are very poor. The grammatical errors here would reinforce an assessment of at least a weak literacy level.

Other connection problems involve logical relationships and their signalling: 
(15) Cadmium is extremely toxic, so anyone that may be aware of these coils could be in danger; therefore they must be separated from common areas.

As the statement in the first clause is known to readers, subordinate connection is more suitable (e.g. Because cadmium vapour is extremely toxic...). The possible ambiguity of reference for "they" and the lack of clarity and precision of the two last statements make this extract bewildering at least, and an indicator of a weak literacy level.

\section{Verbose, Repetitive Connections}

The problem with Extracts 14 and 15 is that the writer has connected the material improperly. However, even if the connections are correct the technique can be poor if it is achieved in a verbose and repetitive manner:

(16) The next hazardous area is the first floor. The first hazard is located in room 109. On the wall there is an amp switch which is rusted, this should be replaced by a new one. There are corroded valves as well which need replacement because they are leaking water on a socket. The last hazard on the first floor is a glass door. The glass door is used to open in an emergency because the fire equipment is stored behind it. The problem is that this door has been cracked, people could walk by and cut themselves. This needs to be replaced as well.

This extract has 10 brief "sentences," including those connected by comma splices, and the first and sixth "sentences" are unnecessary. In addition, eight sentences start with "The," “This," or the existential "There," indicating a very weak "vocabulary" of sentence connections. The writing style together with other ideological and grammatical errors, indicates a low literacy level, though perhaps not enough to fail the student. Repetitive use of the existential there as a sentence starter and elsewhere was very common many of the tested students, who appeared to be trying to find a single "formula" sentence pattern to use most of the time. Such lack of variety itself is an indication of weak writing ability. 


\section{Expectations and Aims}

\section{Technical Level and Vocabulary}

The test described here is given to all first-year engineering students in their first week of classes. Obviously, we cannot expect them to know very much about technical matters at that early stage in their engineering careers, or to have developed a great technical vocabulary. In an effort to overcome this difficulty, the test contains few technical terms and the subject matter is of a general nature rather than being specifically technical. Often technical terms are defined, explained or spelled out for students; an example in an earlier test was the term "detritus" from a tree, which was defined as anything (leaves, twigs, flowers, etc.) falling from the tree. In addition, judges are all aware that these are first-year students and make their assessments accordingly.

On the other hand, the students are expected to understand the words of general vocabulary contained in the information presented to them. They are also expected to follow the written instructions given, to understand the information presented to them, to organise the material in a sensible order, and to communicate all important information in a clear manner following accepted principles of the language. They should be able to understand the separate items of information in enough detail so that they can create a reasonably coherent, complete, and correct overall message for the defined purpose. The test may not be one that fully evaluates the students' ideological literacy of a job-related assessment, as that would be inappropriate for a university admissions test. However, it is a close approximation to such a test, while recognising and taking account of the students' expected levels of technical knowledge and assumed lack of experience with functional writing.

\section{Relevance}

The concept of relevance is also introduced in the test described here. Information of little relevance to the purpose of the document is deliberately included in the information provided to students. They are expected to recognise lack of relevance and to exclude that information from their written document. This technique was used by Winter (1976), who, in giving information for students to organise into a recognisable problem/ solution pattern, also included material that did not contribute to the 
information types and was thus irrelevant. Even though some of his students (all Norwegian) had quite serious difficulties writing technical English, he reported that few failed to recognise irrelevant material. A similar result is apparent with this test, although the weakest students do have difficulty and this is another indicator of a low level of literacy.

The meaning of relevance used for the test does not follow the cognitive principles of "relevance theory" advocated by Sperber and Wilson (1986) and others. (See the Journal of Behavioral and Brain Sciences, 10(4), 1986 , for a wide-ranging analysis of the theory.) Rather, it adapts principles of "Relevance to what?" and "Relevance for what purpose?" discussed by Clark (1987), and related work by Sanders (1987:82), Mey and Talbot (1988), Gorayska and Lindsay (1993), and others who criticise the theory. Jordan (1988) provides a recent review and text-based criticism of the cognitive approach, together with a detailed explanation of the concept of relevance used for the test described here. As an example, the fact that Dr. Harty has just had an article on storm warning devices in aircraft published in Flight is irrelevant for an accident report described for this test. It is irrelevant because it does not contribute to achieving the purpose of the communication. Few students included that information, and many grinned with instant recognition of irrelevance when they heard it.

\section{Simulating Reality}

We must recognise that no writing test can simulate a job-related situation completely. Students do not have access to spell, grammar, or style checkers as they will in actual job conditions, though almost all of the serious ideological errors would not be noted or corrected by any of these. Students also cannot ask for clarification as they might be able to do in some real situations. However, part of the test is to determine whether students can, without significant loss due to language problems, learn from the traditional lecture teaching method of higher education, and so this feature is retained deliberately. Few students have ever written anything functional (as opposed to expressive or literary) in their lives, but this is not a problem for those with reasonable language and communicative skills, as the format and purpose instructions provided are adequate. We thus regard the test as an acceptable, though clearly not ideal, method of assessing 
comprehension and ideological writing skills in English.

The attempt in designing the test is to simulate as closely as possible a real-life, job-related activity with the constraints imposed by the educational environment for first-year students. The test thus provides all the information needed and includes elements of written and oral comprehension as well as writing for a specific reader, for a specific purpose, in a specific given format. The information is given slowly-and repeated if necessary - to give students every reasonable opportunity to understand and note the information being provided. The students then have ample time- usually 75 minutes or more-to complete the task; few students have not finished by that time.

In contrast, TOEFL scores have little bearing on a student's ability to write in practical circumstances, precisely because they test only grammatical knowledge in an acontextual, multiple-choice environment. Many of the questions can be learned by rote, and they are not designed to evaluate word choice, meaning or communicative precision or completeness. Their great advantages are their apparent objectivity and their relative low cost. The reason for the test described here is that some students with TOEFL scores that are sufficiently high for admission nevertheless exhibit both autonomous and ideological illiteracy.

The essay subjects used for the TOEFL writing scores are much more appropriate as a guide to academic writing ability, but the questions are without realistic situational or content constraints. More seriously, perhaps, students can practice writing the few types of questions set, with a fair chance of having something they have studied and learned largely by rote. They can also learn many sentence patterns by rote and thus produce some high-functioning patterns of the language to give a false impression of writing ability. In addition, the TOEFL questions bear no relation to any functional document relating to their chosen technical professions. The assessment of TOEFL essay questions is no more objective than the one described here.

\section{Conclusions}

The attempt here has been to lay the groundwork for a detailed language-based definition of basic functional literacy in terms of a complex amalgam of grammatical, sociolinguistic, and discourse competence (Duran et al, 1985). As the grammatical difficulties of technical students are well known, this analysis has concentrated on sociolinguistic (or job-related or 
"ideological," Street [1984]) competence, with some discussion of serious weaknesses of discourse competence. Sociolinguistic competence is poorly described in ESL texts, and is only partly recognised in even the best texts in technical writing. Thus, this area of literacy-and instruction in technical writing-deserves greater attention from linguists and writing teachers.

By a complex amalgam of competence, I mean that grammatical and sociolinguistic elements of literacy are of equal importance and are both necessary elements of literacy. That is, we should not allow serious grammatical deficiencies to be "balanced out" by superb technical contentor the other way round. Basic functional literacy for technical and engineering students means that they can communicate reasonably complete and exact technical material in a reasonably acceptable way. That, after all, is the minimum level for professional competence as defined by the PEO Kantor case.

The literacy level that each engineering department or faculty hopes to attain should depend on the level of their follow-up course(s) in technical writing and also which topics they cover and to what depth. Units that provide several courses over several years may be able to accept weaker students. On the other hand, those that provide little formal instruction in effective technical communication would be wise to establish a higher level of literacy for those entering their first writing course. If there is no followup instruction and practice in technical communication, much more emphasis should be placed on discourse and strategic competence. The emphasis on the grammatical/ sociolinguistic balance may also need to change. This balance might depend, for example, on whether students' later writing work is assessed only by technical teaching assistants with weak (sometimes extremely weak) literacy levels themselves, or only by language teachers with little technical background.

Society, industry, the Canadian Engineering Accreditation Board, and provincial engineering associations need to recognise that we can no longer graduate students who cannot take their professional place with their peers because of a low level of literacy in English (see Friere's [1974]) definition of literacy noted earlier). Such professional pressure may become more important as some universities and colleges, under financial pressure, are being tempted to lower admissions standards without determining their students' writing skills under test conditions, and without insisting that weak students upgrade their writing skills to an acceptable level. In particular, Engineering faculty who allow students to graduate with literacy 
levels like that shown in the Kantor summary may well be found guilty of professional misconduct themselves-and so could members of professional associations or accreditation committees who allow the practice to continue. Clear accountability is necessary.

Unfortunately, the language abilities of some graduate students are sometimes more wanting than those of undergraduates. Many of them serve as engineering teaching assistants, posing a possible safety risk and often adversely affecting the learning environment. This may be caused, for example, by inaccurate instructions or unclear advice regarding laboratory work dealing with electrical power or chemicals. More seriously, though, many are allowed to graduate from English-speaking universities in Canada although they are not sufficiently competent in written English. This does a grave disservice to the students themselves, as well as to the reputation of the institution and the profession. While institutions continue to accept enrolment income from students without insisting on basic language competence and without providing related courses, this situation is unlikely to improve.

The need for recognition of levels of basic functional literacy has never been greater, and is likely to increase. Until accreditation boards and professional associations insist on tested levels of literacy for acceptance into Canadian specialities and professions, universities and colleges would be wise to establish, test, and insist on their own minimum standards of literacy.

\section{References}

Askov, E.N. (1993). Approaches to assessment in workplace literacy programs: Meeting the needs of all the clients, Journal of Reading, also in Radencich (1994), 262-267.

Askov, E.N., \& Aderman, B. (1991). Understanding the history and definitions of workplace literacy. In M.C. Taylor, G.R. Lewe, \& J.A. Draper (Eds.), Basic Skills for the Workplace (pp. 7-20). Toronto, ON: Culture Concepts.

Chisholm, F.P., \& Campbell, W.L. (1990). Leadership for Literacy. San

Francisco, CA: Jossey-Bass. 
Clark, H.H. (1987). Relevance to what? Journal of Behavioral and Brain Sciences, 10(4), 714-715.

Crawford, S. (1995). Writing errors of engineering students: A diagnostic analysis, Technostyle, 12(2), 77-85.

Duran, R., Canale, M., Penfield, J., Stanfield, C.H., \& Liskin, E. (1985). TOEFL from a communicative viewpoint on language proficiency: $A$ working paper, (Report 17 R, pp. 85-88). Princeton, NJ: Educational Testing Service.

Friere, P. (1974). Pedagogy of the Oppressed. Harmondsworth: Penguin.

Goody, J. (1968). Literacy in Traditional Societies. Cambridge, England: Cambridge University Press.

Gorayska, B., \& Lindsay, R. (1993). The roots of relevance. Journal of Pragmatics, 19, 301-323.

Gray, W.S. (1956). The Teaching of Reading and Writing. Chicago: Scott Foresman.

Hirsch, E.D., Jr. (Ed.) (1987). Cultural Literacy. Boston, MA: Houghton Mifflen.

Jordan, M.P. (1998). The power of negation in English: Text, context and relevance. Joumal of Pragmatics, 29, 1-48.

Langer, J.A. (1987). A sociocognitive perspective on literacy. In J.A.Langer (Ed.) Language, Literacy and Culture: Issues in Society and Schooling, (1-20). Norwood, NJ: Ablex.

Lankshear, C. (1986). Humanizing functional literacy: Beyond utilitarian necessity. Educational Theory, 36 (4).

Lankshear, C., \& Lawler, M. (1987). Literacy, Schooling and Revolution. New York, NY: Falmer Press.

Mey, J.L., \& Talbot, M. (1988). Computation and the soul.Journal of Pragmatics, 12, 743-789.

Mikulecky, L., \& Drew, R. (1991). Basic literacy skills in the workplace. In R. Barr, M.L. Kamill, P. Mosenthal, \& P.D. Pearson (Eds.), Handbook of Reading Research. White Plains, NY: Longman. 
Nafzinger, D.H., Thompson, R.B., Hiscox, M.D., \& Owen, T.R. (1976). Tests of Adult Functional Literacy: An Evaluation of Currently Available Instruments. Portland, OR: Northwest Regional Educational Laboratory.

National (USA) Assessment of Educational Progress. (1986). Profiles of Literacy: An Assessment of Young Adults. Princeton, NJ: Educational Testing Service.

O'Neil, W. (1970). Properly literate. Harvard Educational Review, 40(2), 260 263.

PEO (1987). Summary of disciplinary hearing in the matter of Mark G. Kantor, P. Eng. Engineering Dimensions Gazette, (p. 6) Toronto, ON: Professional Engineers of Ontario.

Purves, A.C. (1987). Literacy, culture and community, In D. Wagner (Ed.) The Future of Literacy in a Changing World, (pp. 216-232) Oxford: Pergamon Press.

Purves, A.C., \& Takala, S. (Eds.). (1982). An international perspective on the evaluation of written composition-Evaluation in education. An International Review Series, 5(3). Oxford: Pergamon Press.

Radencich, M.C. (Ed.). (1994). Adult Literacy: A Compendium of Articles from the Journal of Reading. Newark, DE: International Reading Association.

Sanders, R.E. (1987). Cognitive Foundations of Calculated Speech: Controlling Understandings in Conversation and Persuasion. Albany, NY: State University of New York Press.

Sperber, D., \& Wilson, D. (1986). Relevance: Communication and Cognition. Oxford: Basil Blackwell.

Statistics Canada. (1995). Literacy, Economy and Society. Ottawa, ON: Organisation for Economic Co-operation and Development.

Street, B.V. (1984). Literacy in Theory and Practice. Cambridge, England: Cambridge University Press.

Street, B.V. (1994). Struggles over the meaning(s) of literacy. In M. Hamilton, D. Barton, \& R. Ivanic (Eds.) Worlds of Literacy, (pp. 15-20). Toronto, ON: Ontario Institute for Studies in Education.

Stubbs, M. (1986). Language and Literacy. London: Routledge \& Paul Kegan. 
UNESCO. (1957). World Literacy at Mid Century, Paris, France: UNESCO.

Winter, E.O.O. (1976). Fundamentals of Information Structure. mimeo. Hatfield, England: School of Humanities, Hertfordshire University.

Wormald, C.P. (1977). The use of literacy in Anglo-Saxon England and its neighbours. Transactions of the Royal Historical Society, 5th series.

\section{Appendix A}

\section{Written Instructions for the Test of Written English}

Background: Assume that you are a Safety Inspector and have just completed your annual inspection of the Bondar Building. Your task is to report your findings to the Head of the Department of Aeronautical Engineering, Dr. S. Harty.

Format: Write the report on the memo paper provided, completing all parts. Use blank paper if you need a second sheet.

Contents: The information to be included will be given to you orally in a deliberately verbose and disorganised manner, and perhaps with some irrelevant information. Do not add any other information.

Your task: Take notes from the information provided, delete irrelevant information, and re-organise the remaining information. Then, write a clear, concise, and technically precise report in complete, well-formed sentences. DO NOT OMIT IMPORTANT INFORMATION. Punctuate your writing and use paragraphs appropriately.

Conditions: We expect you to comply with Queen's EXAMINATION CONDITIONS throughout this test.

Timing and Identification: You will be given about an hour to complete the report once the information has been provided. Write your student number at the top of your memo; do not include your name anywhere on your work. 


\section{Oral Text for the Test of Written English}

March 18, 1997

Good morning. Here is the information on which you should base the memo that you are about to write.

You are writing this memo to Dr. S. Harty. Her last name is spelled “H A R T Y”. As you know, her full name is Dr. Susan Rebecca Harty. She is the Head of the Department of Aeronautical Engineering and has just written a very interesting article on storm warning devices in aircraft. This article has just been published in a magazine called Flight.

The inspection that I am providing information about was conducted by you earlier today and there were many problems that you have identified. These all need the immediate attention of Dr. Harty to whom you are sending this memo.

On the second floor, in the corridor, and about half way down the corridor you found a normal drinking fountain with a protective lip designed to prevent people from putting their mouths down over the part where the water comes out and thereby preventing any transmission of disease. Unfortunately, that metal lip on this particular drinking fountain has been broken off and this obviously presents a hazard because people could cut their mouths when they try to take a drink. Also there could be a transmission of disease as a result of people putting their mouths down too far. So, that obviously needs to be fixed.

Down in the basement, in the wind tunnel laboratory, there is a quite a large pool of oil in the Northwest corner of the laboratory. Someone has sprinkled sawdust over this pool of oil, but obviously it needs to be cleaned up properly and the floor needs to be kept free of oil and grease at all times.

In room 105 there is an exit sign on the south wall and one of the two bulbs in that exit sign is not working. On the second floor in the faculty lounge there is a new coffee machine. The problem is that an extension cord is being used to connect the coffee machine to the electrical socket and of course, that is totally unacceptable. Another problem related to this socket is that it is being used for the coffee machine and also for the kettle 
and the microwave oven. This is quite unsafe. The way to fix this is to wire a separate permanent circuit for the coffee machine. The coffee machine is not to be used until that permanent circuit is in place.

By the way, the name of the building that you inspected is the Bondar building. It is named after Roberta Bondar who was the first female Canadian astronaut. Bondar is spelled "B O N D A R".

On the first floor in room 109 there is a large $50 \mathrm{amp}$ switch. It is on the South wall of the room and it is quite badly rusted and should be replaced. Just below that switch, on the same wall, there are two heat control sensor switches which measure the room temperature. They control valves that turn the hot water supply to the radiator on or off in order to provide heat to the room. These valves, located just below the sensors, are very badly corroded. In fact, they are dripping water and the water, which is rusty water, is dripping down the wall and creating quite a mess as well as a safety hazard. So they need to be fixed too.

In the basement corridor at the north end there is an exit going outside and this is partly obscured by three large garbage cans. These cans need to be removed and stored somewhere. On the north wall of room 206 there is an exit sign that is not lit at all. This shows people how to get out of an emergency exit on to a fire escape. The fire escape that they point to has quite a heavy accumulation of ice and this of course could prove quite hazardous during any emergency use.

You should note somewhere in your memo that you will be coming back in a couple of weeks to check that the deficiencies that you have identified have in fact been fixed.

Down in the welding shop, and this is in the basement, you found some loose coils of cadmium solder. Cadmium is spelled "C A D M I U $M$ ". You, as safety inspector, know that cadmium is extremely toxic and because of there are some very rigid requirements as how it is used and handled. Warnings about the safe handling and storage of cadmium solder are always included on the box containing the coils. You found loose coils sitting out away from the box and anyone picking up these coils would not necessarily be aware of the warnings that are on the box which is somewhere else. So, first of all, you need to point out that the coils should never be separated from the box and therefore from the warnings contained on the box and also you should suggest that the department review its training and its procedures for the use of cadmium solder and also for the storage of this material. 
The second floor has a Xerox room. There is not a number for it so I cannot give you a number but it is on the second floor, beside the main departmental office. In this Xerox room there is a metal cabinet on top of which there is an old typewriter. Balanced on top of the old typewriter there are several heavy files. Obviously, these could fall and they could hurt someoneThe cabinet could be knocked causing the files to fall and cause an injury so these files need to be stored more securely than they are at present.

The final thing that you noticed in your inspection is that on the first floor, half way down the corridor, there is the usual fire fighting equipment which is secured behind a glass door which is locked. The trouble is that this glass door has been cracked quite badly and anyone running their hand across the glass without looking could suffer a very serious cut so this needs to be remedied.

This is all the information you have. Start writing your memo.

\section{Appendix B}

\section{Example Student Test of Written English}

\section{Queen's University Memorandum}

To: Dr. S. Harty, Head, Department of Aeronautical Engineering

From: (student number)

Date:

Subject: Safety Inspection Bondar Hall

I conducted the annual external safety inspection of your building earlier today and found the following deficiencies which need your immediate attention.

There is a sizable pool of oil in the north-west corner of the wind tunnel laboratory. Someone had sprinkled sawdust over it, but it needs to be cleaned up properly and the floor kept free of oil and grease at all times. The external door at the north end of the basement corridor is partly obscured by three large roller bearings, which need to be removed. I found some loose coils of cadmium solder in the welding shop. Because of the extreme toxicity of cadmium, this solder should never be separated from 
the box containing all the warnings; also please review your training and procedures for the storage and use of this material.

One of the two bulbs in the EXIT sign on the south wall of Room 105 is not working. The 50 A double-pole switch on the wall of Room 109 is badly rusted and needs replacing. Also the two heat control sensor/ switches above this electrical switch are badly corroded, and rusty water is dripping down the wall. A further problem on the first floor is a badly cracked glass covering the fire-fighting equipment half way down the corridor; this could cause a serious cut and needs to be renewed.

The protective metal lip on the drinking fountain mid-way down the second-floor corridor has been broken off, presenting a cutting hazard to users and exposing them to the transmission of disease. The EXIT sign on the outside (north) wall of Room 206 is not lit. There is still a heavy accumulation of ice on the fire escape at this emergency exit and this could prove hazardous during emergency use. In the faculty lounge, the new coffee machine is plugged into a socket with an extension lead. A related problem is that this device shares the same socket as the kettle and the microwave oven. The coffee machine must not be used in that location until a separate permanent circuit has been wired for it. Also on the second floor, the xerox room (not numbered) has several heavy files balanced on an old typewriter on top of a metal cupboard. As these could fall and hurt someone, they need to be stored more securely.

I will make a return inspection in two weeks to check that these deficiencies have been remedied. 


\section{Appendix C}

Summary of Disciplinary Hearing

in the Matter of Mark G. Kantor, P.Eng.

(used by permission from Gazette-November/December 1987)

At a Hearing held on April 14, 1987 the Discipline Committee of the Association found Mark G. Kantor, P.Eng., in absentia, guilty of professional misconduct.

Mr. Kantor failed to appear before the Committee nor was he represented by legal counsel. After hearing evidence that Mr. Kantor had been given sufficient and ample notice as to the date, time and place of the Hearing, the Committee decided to proceed without him.

The particulars relating to the charge concern a feasibility study prepared by Mr. Kantor for an electrical energy management program for a manufacturing company.

In reviewing the evidence before it, the Committee concluded that Mr. Kantor's report was so badly written that it could not be sure of exactly what Mr. Kantor was saying or what was meant by some of his statements. The president and general manager of the manufacturing company testified that he was not satisfied with Mr. Kantor's report in regard to the language and the way it was put together, nor did he know whether any of its recommendations had been implemented.

The decision of the Committee was based on the following provisions of Regulation 538/84 made under the Professional Engineers Act, 1984:

\section{Section 86(2)(a): Negligence as defined in Section 86(1). In this Section, negligence means an act or an omission in the carrying out of the work of a practitioner that constitutes a failure to maintain the standards that a reasonable and prudent practitioner would maintain in the circumstances.}

The finding was based on the fact that the feasibility report or study prepared by Mr. Kantor did not meet the criteria generally considered necessary to provide a meaningful electrical engineering report as it contained statements that were poorly written, contradictory and confusing and that it contained errors and indicated a lack of knowledge of the basic theory of electrical engineering. The following are examples from his report included in the allegations: 
For a three-phase power distribution he states:

"From the Aperemeter on the main pannel we can see that overege power consumption within operational shift is 570A or $342 \mathrm{KVA}$. The maximum power consumption of all of the installed electrical equipment (if loading factor would be 1 ) could be $1200 \mathrm{~A}$ or $720 \mathrm{KVA}$."

2. "As a result of such situation, the insulation of the motor's wires are overheated and overdrayed. Therefore, it become a brittle and life of the electrical motors would be drastically reduced."

3. "As a result of the above study we can come to conclusion that there is no economical and not practical to keep the installed capacitors who do not improve the Power-Factor to cat the utility bill, but are creating an excessive voltage rise in long run, would reduce the life of the electrical equipment."

Testimony indicated that the system was operating satisfactorily without changing capacitors as recommended.

4. "Existing Power-Factor is low than $90 \%$ and therefore there are no benefit from the existing capacitors" and "the installed capacitors which do not improve the Power-Factor to cat the utility bill" were contradictory to another statement in the report: "When all three capacitors are turned on the Voltmeter show 640V and Power-Factor meter show .91-.93."

5. "Such voltage overload would drastically reduce the electrical motor's lifes and require a more often and carrefull [sic] maintenance of electrical connection, swithes, etc."

6. "Because absentes of adequate insulation, the heaters are using electric power permanently and company pay a lot of money for these." 
Section 86(2)(g): Breach of the Act or Regulations, other than an action that is solely a breach of the Code of Ethics.

The Committee found that Mr. Kantor was in breach of the Professional Engineers Act and its Regulations in that he offered to the public services that fall within the practice of professional engineering without holding a Certificate of Authorization.

Section 86(2)(j): Conduct or an act relevant to the practice of professional engineering that, having regard to all the circumstances, would reasonably be regarded by the engineering profession as disgraceful, dishonourable or unprofessional.

The Committee considered that Mr. Kantor's conduct was indeed unprofessional, but was not disgraceful or dishonourable. 